\title{
PSC-induced Galectin-1 Promotes the Malignant Behavior of Pancreatic Ductal Adenocarcinoma
}

\author{
Dong Tang ${ }^{1}$, Qi Wu ${ }^{2}$, Hong Peng Zhang ${ }^{1}$, Zhong Xu Yuan ${ }^{3}$, Jia Ming Xu ${ }^{1}$, Han Jian Zhu ${ }^{1}$, Jin Gao ${ }^{1}$, \\ Zhuang Zhuang Liu ${ }^{1}$, Zhu Jiang Dai ${ }^{2}$, Xiao Ming Sun ${ }^{2}$, Meng Yue Xu', Hui Wen Fang ${ }^{2}, Z_{\text {hen }}$ Li $^{2}$, \\ Chao Biao Lin ${ }^{2}$, Chun Feng Shi ${ }^{2}$, Dao Rong Wang ${ }^{1}$
}

\begin{abstract}
${ }^{1}$ Department of General Surgery, Institute of General Surgery, Clinical Medical College, Yangzhou University (Northern Jiangsu People's Hospital), Yangzhou, Jiangsu 225001, China; ${ }^{2}$ Department of Clinical Medicine, Medical College of Yangzhou University, Yangzhou, Jiangsu 225001, China; ${ }^{3}$ Department of General Surgery, Anhui No. 2 Provincial People's Hospital, Hefei, Anhui 230041, China
\end{abstract}

Abstract: Background Galectin-1 is a $\beta$-galactoside-binding protein overexpressed in the pancreatic stellate cells (PSCs) of pancreatic ductal adenocarcinoma (PDAC), while its expression is typically low in pancreatic cancer cells (PCCs). The point at which galectin-1 expression in PCCs increases, and its association with PDAC progression, have been unclear. Methods Galectin-1 expression in PDAC and metastatic lymph nodes was investigated using an immunohistochemical assay. PANC-1 PCC cells were co-cultured with PSCs expressing different levels of galectin-1. Subsequently, galectin-1 was overexpressed in PANC-1 cells using recombinant lentiviruses, and their proliferation, invasion, anchorage-independent growth, and in vivo tumorigenicity were evaluated. Results There was intermediate galectin-1 expression in PCCs, and it was positively associated with galectin-1 expression in PSCs in the PDAC tissues. Galectin-1 was strongly expressed in the metastatic lymph nodes. In the co-culture, high galectin-1 expression in the PSCs increased the galectin-1 expression in the PANC-1 cells. The galectin-1 overexpression in the PANC-1 cells enhanced their clone formation ability, proliferation, and invasion, increased the expression of proliferating cell nuclear antigen (PCNA) and BCL-2, and decreased Bax expression, promoting the establishment and growth of tumors. Conclusion High galectin-1 expression in PSCs induces galectin-1 expression in PCCs and subsequently promotes the malignant biological behavior of PDAC.

Key words: Pancreatic ductal adenocarcinoma; Pancreatic stellate cells; Galectin-1; Invasion; Metastasis

\section{Introduction}

Pancreatic ductal adenocarcinoma (PDAC) has a high mortality rate [1]. The poor outcome of PDAC is related to its aggressive growth and rapid progression of distant metastases, low rate of surgery, and resistance to chemoradiation, making treatment extremely challenging [2]. At diagnosis, $50 \% \sim 60 \%$ of patients already have advanced disease with distant metastases, and of the $10 \%$ or so of patients who are able to undergo curative resection, many will relapse with distant metastasis and/or locoregional disease [3,4]. In terms of histopathology, PDAC often occurs with a dense desmoplastic reaction [5]. This histological type composes approximately $80 \%$ of the tumor, and is not just a passive tumor

Dong Tang, Qi Wu and Hong Peng Zhang made an equal contribution to this paper.

Corresponding authors: Dong Tang, MD, PhD, Department of General Surgery, Institute of General Surgery, Clinical Medical College, Yangzhou University (Northern Jiangsu People's Hospital), Yangzhou 225001, China; Tel: +86 1895278 3556; Email: 83392785@qq.com; Dao Rong Wang, MD, PhD, Department of General Surgery, Institute of General Surgery, Clinical Medical College, Yangzhou University (Northern Jiangsu People's Hospital), Yangzhou 225001, China; Tel: +861390525 2590; Email: daorong666@sina.com cell scaffold, but is actively involved in carcinogenesis [6]. The cellular component driving this desmoplastic response is pancreatic stellate cells (PSCs), pancreatic stromal cells with quiescent and activated states [7,8]. Growing evidence has demonstrated that the interaction between PDAC cells and activated PSCs plays an important role in PDAC development. The PSCs create a hypoxic and desmoplasia microenvironment that can promote PDAC initiation, invasion, evasion of immune surveillance, chemoradiation resistance and metastasis by generating high levels of chemotactic factors, cytokines, growth factors, and excessive extracellular matrix (ECM) [9-14]. Therefore, targeting the PSC and PDAC cell interaction could represent a new treatment option for advanced PDAC, especially treatments that target PSCs in the microenvironment of PDAC $[2,6,15]$. However, despite increasing attention being focused on the tumor microenvironment, there is not a comprehensive understanding of the specific functions and effects of PSCs in PDAC.

Galectin-1 (LGALS1), a member of the galectin family of $\beta$-galactoside-binding proteins, is a homodimer comprising $14-\mathrm{kDa}$ subunits with two $\beta$-galactoside-binding sites [14]. The biological functions of galectin-1 include cell-matrix and cell-cell communication and cell proliferation [16]. Increased evidence has indicated that the 
expression of galectin-1 is increased in tumors, indicating that it is involved in tumor cell invasion and the formation of metastasis [17], increasing tumor angiogenesis [18], and defending tumors from host immune responses [14,19]. Galectin-1 also plays a role in the desmoplastic reaction that appears around PDAC cells [20]. Galectin-1 was overexpressed in single culture activated PSCs and promoted PSC proliferation and chemokine production [20,21]. We have shown that, in PDAC, galectin-1 is mostly expressed in activated PSCs and can significantly boost tumor cell growth, progression, and proliferation, and contributes to a poorer outcome $[22,23]$. In addition, galectin-1 is weakly expressed in pancreatic cancer cells (PCCs), but is strongly expressed in metastatic peripancreatic lymph nodes [23]. Although the galectin-1 expression in PDAC tissues has been profiled, the specific function of endogenous galectin-1 expressed by PSCs in the PDAC microenvironment and its expression in PCCs have not been characterized.

We investigated the influence of different galectin-1 levels in primary PSCs on the galectin-1 protein expression profile of PCCs and examined the correlations of the molecular findings to determine whether the different galectin-1 levels in PCCs: i) promote cancer cell proliferation, anti-apoptosis, and invasion; ii) have the capacity to promote tumor establishment and growth.

\section{Materials and Methods \\ Patients and pancreatic tissues}

A total of 66 malignant pancreatic tumor samples and 18 chronic pancreatitis tissue specimens were included in the present study. The pancreatic cancer patients comprised 45 men and 21 women with a median age of 55 years (range, 37 83 years), and the chronic patients comprised 13 men and 5 women with a median age of 54.5 years (range, 27 71 years). The tissues adjacent to the specimens were evaluated histologically according to the criteria of the World Health Organization, and the tumor pathological stage was classified according to the International Union Against Cancer Classification (UICC). More detailed information on the clinicopathological characteristics of patients, PDAC tissues, and the histological evaluation of the PDAC tissue specimens have been described previously [14,23,24].

\section{Ethics statements}

All patients provided informed consent for their cooperation in the research study, which was authorized by the Ethics Committees of each institution. A copy of the consent form for each patient is readily available upon request.

All animal experiments were accomplished in line with the guidelines of the Experimental Animal Center Institutional Committee of Yangzhou University for Care and Use of Laboratory Animals. The procedures performed on animals, feeding conditions and the method of execution have been described previously [23].

\section{Immunohistochemical staining and evaluation}

Hematoxylin and eosin (H\&E) staining and immunohistochemical staining were carried out as previously reported $[14,23]$. The primary antibodies were mouse monoclonal anti-galectin-1 (sc-166618; 1:200; Santa Cruz Biotechnology, Inc., Santa Cruz, CA, USA) and anticytokeratin 19 antibodies (1:200; MA106329; ABR, USA). Five fields $(\times 200)$ were randomly counted for each sample.

\section{Cells and culture conditions}

The methods of primary human PSCs identification, isolation, maintenance were described previously [14,23,24]. Passage number 2 5 PSCs were utilized for all analyses. PANC-1 cells were maintained in DMEM supplemented with 10\% FBS. Co-culture experiments were carried out as follows: monolayers of PSCs $\left(1 \times 10^{5}\right.$ cells $)$ and PANC1 cells $\left(5 \times 10^{5}\right.$ cells $)$ were respectively cultured in the upper and lower chambers of transwells (six-well, 0.4-Km, Corning, NY, USA) at $37^{\circ} \mathrm{C}$. Proteins were extracted from PANC-1 cell lysates after the co-culture.

\section{Quantitative reverse transcription-polymerase chain re- action}

Total RNA was extracted from cultured cells using the Trizol reagent (Invitrogen, Beijing, China) according to the manufacturer's instructions. QRT-PCR was performed using a SYBR Premix Ex Taq Reverse Transcription-PCR kit (TaKaRa, Shiga, Japan). The following primers were used: galectin-1 forward 5'- GAGGTGGCTCCTGACGCTAA-3' and reverse 5'-CCTTGCTGTTGCACACGATG-3', and b-actin forward 5'- AGAAAATCTGGCACCACACC-3' and reverse 5' - TAGCACAGCCTGGATAGCAA-3'. $\beta$-actin was used as an internal control for comparison of the data. Quantitative PCR was performed using the ABI PRISM 7500 Fast Real-Time PCR System (Applied Biosystems, Carlsbad, CA, USA), and the comparative $\mathrm{Ct}$ method was used to assess relative differences in mRNA levels between two samples. All samples were run in triplicate.

\section{Western blotting analysis}

Western blotting was carried out as reported previously $[14,23,25]$. In brief, cells were lysed in SDS buffer and total cellular proteins $(100 \mathrm{mg})$ were separated on $10 \%$ or 10\%-20\% gradient SDS polyacrylamide gels, transferred to PVDF membranes, and incubated with mouse anti-Galectin-1 (sc-166618;1:200; Santa Cruz Biotechnology, Inc., Santa Cruz, CA, USA), anti-Bcl-2 (1:200; sc-509, Santa Cruz Biotechnology, Santa Cruz, CA), anti-Bax (1:200; sc7480, Santa Cruz Biotechnology, Santa Cruz, CA), and anti-PCNA (1:200; sc-53407, Santa Cruz Biotechnology, Santa Cruz, CA) antibodies overnight at $4{ }^{\circ} \mathrm{C}$. After incubation with peroxidase-conjugated rabbit anti-mouse $\mathrm{IgG}$ antibody (Cell Signaling Technologies, Beverly, MA, USA), proteins 
were visualized using an ECL system (GE Healthcare, Chalfont St. Giles, UK). Alpha-tubulin was used as a loading control.

\section{Preparation and transduction of recombinant lentivi- ruses}

The plasmids utilized to prepare recombinant lentiviruses to induce galectin-1 overexpression in PSCs or PANC1 cells have been described previously [14]. In brief, the human galectin-1 gene fragment was cut out from a human cDNA library and cloned into pHAGE-CMV-MCS-IZsGreen between the BamHI and XhoI restriction enzyme sites. The methods used to infect the PSCs or PANC-1 cells, perform cell selection, and identify the viruses were reported previously [14].

\section{In vitro proliferation assay}

The proliferation of PANC-1 cells was tested using the methyl thiazolyl tetrazolium (MTT) (Sigma, USA) assay as described in a previous publication [22]. Galectin-1 overexpressing PANC-1 cells $\left(2.5 \times 10^{3}\right)$ or normal control cells were placed in 96-well plates. We used $10 \%$ FCS to culture PANC-1 cells for 12 hours, until the cells adhered to the plate. The culture medium was then changed, and the proliferation levels were detected after 24, 48, 72, and $96 \mathrm{~h}$. The results were determined by absorbance $(570 \mathrm{~nm})$ in a microtiter plate reader.

\section{In vitro invasion assay}

The Matrigel invasion assay was applied to evaluate the ability of PANC- 1 cells with and without overexpression of galectin-1 to infiltrate the ECM. The method used has been described in a previous publication [23].

\section{Wound healing assay}

PANC-1 cells were placed in 24-well plates and allowed to proliferate to confluence. After being serumstarved for 12 hours, the monolayer cells were wounded by scraping off a band of cells with a pipette tip (200 $\mu \mathrm{L})$. The cells were cultured for an additional 24 hours after wounding, then cells were fixed. Photographs were taken of three different segments of the 'wound' area in each well, and the cell numbers inside the wound boundaries were counted.

\section{Assay for Ethynyl Deoxyuridine (EdU) incorporation}

To assess the in vivo cell proliferation, mice were intraperioneally injected with $100 \mu \mathrm{g}$ of EdU in PBS. After 4 hours, the tumor tissues (PANC-1) were collected from mice, sectioned, subjected to immunohistochemistry and observed under an optical microscope as described previously [26].

We randomly selected 5 groups of confluent cells from each sample image to count the number of EdU-positive cells. The relative positive ratio was determined from the average of the five group values.

\section{Assay for anchorage-independent growth}

An anchorage-independent growth assay was performed as described previously [27]. Experiments were carried out in 6-well dishes coated with $1 \%$ agarose (in DMEM with $10 \% \mathrm{FBS}$ ). One thousand cells were equably suspended in $0.5 \%$ agarose/DMEM and allowed to adhere to the bottom. The dishes were kept at $4^{\circ} \mathrm{C}$ for 2 hours to allow the agarose to solidify, then were incubated at $37^{\circ} \mathrm{C}$. After 24 hours, fresh medium $(2 \mathrm{ml})$ was added on the agar. The medium was replaced every 2 days. After 14 days, we counted the colony numbers and photographed the colonies by phase-contrast photomicrography. Only colonies $\geq 0.1 \mathrm{~mm}$ in diameter were counted.

\section{TUNEL assay}

The TUNEL assay was performed as described previously [28]. We counted the apoptotic cells (green staining) under a microscope (x200), and the apoptosis rate was calculated based on the proportion of stained cells among all cells in each sample. Four fields (100 cells/field) were randomly counted for each group.

\section{In vivo models}

The animal experiments were performed according to our previously described research $[23,29]$. In brief, xenograft tumors ( $n=4$ /group) were generated by embedding PANC-1 cells subcutaneously (SC) on both flanks of made nude mice (the left sides were injected with the galectin-1 overexpressing PANC-1 cells, and the right sides were injected with normal control PANC-1 cells) utilizing a 25 -gauge needle. We measured the tumor size using calipers, and the volume was estimated by the formula: length $\times$ width $\times$ depth $\times 0.5236$, as described previously [23]. The animals were sacrificed on day 30 post-implantation using an overdose of Nembutal.

\section{Statistical analysis}

The results are shown as the means \pm standard deviation. The differences between groups were evaluated using t-tests and one-way ANOVAs. The relationship between the expression of galectin-1 in PSCs and in PCCs was evaluated by Pearson's correlation test. $P$-values $\leq 0.05$ were considered to be statistically significant. All statistical analyses were carried out using the SPSS 19.0 software.

\section{Results}

Galectin-1 in PCCs is linked to galectin-1 expression in PSCs and the malignant behavior of PDAC

We previously showed that galectin-1 staining was mostly detected in the PDAC and chronic pancreatitis stroma (the activated PSCs) [30] (Figure 1a), and that the total galectin-1 staining was associated with lymph node metastasis, perineural invasion, increased tumor size, 
tumor differentiation, and the International Union Against Cancer (UICC) stage, with high expression predicting a poor outcome for PDAC [23,24]. However, in the present work, there was obvious galectin-1 staining in some PSCadjacent PCCs (Figure 1), and the number of PCCs with galectin-1 staining correlated significantly with PDAC differentiation, where there were markedly more PCCs with galectin-1 staining in poorly differentiated tissue than in well- or moderately-differentiated tissue $(P=1.01 \times$ $10^{-13}, P=6.54 \times 10^{-8}$, respectively). There were also more PCCs with galectin-1 staining in moderately-differentiated tissues than in well-differentiated tissues $(P=0.0014)$ (Figure 1b-d). A Pearson correlation analysis showed positive correlations between the number of PCCs with galectin-1 staining and the average density of galectin-1 staining in PDAC $\left(\mathrm{r}^{2}=0.78, P=9.78 \times 10^{-23}\right)$ (Figure 1f). In addition, when there was high expression of galectin-1 in the PDAC stroma, it was also strongly expressed in the metastatic PCCs in the metastatic lymph nodes (Figure 1e-g). These results imply that high galectin-1 expression in PSCs may induce galectin-1 expression in some PCCs that are in proximity to PSCs, which may then initiate or support the malignant biological behavior of PDAC and eventually lead to metastasis.

\section{High galectin-1 expression in PSCs upregulates galectin-1 expression in PCCs}

To clarify the impact of PSC-derived galectin-1 on the galectin-1 expression profile in PCCs, we first detected the galectin-1 levels in normal human PSCs (hNPSCs) and PCC lines (SW1990, BxPC-3, PANC-1, CFPAC-1). qRT-PCR and Western blotting showed that the hNPSC galectin-1 levels were obviously higher than those in the PCC lines (Figure 2a). However, co-culture with PSCs exhibiting high galectin-1 expression significantly increased the galectin-1 levels in the PCC lines compared to the levels in single-cultured PCCs $(P<0.05)$ (Figure $2 b)$. To verify that endogenous galectin-1 in PSCs induces galectin-1 expression in PCCs, $\beta$-lactose $(50 \mathrm{mM})$ was used as a galectin-1 antagonist in the co-culture system. Treatment with $\beta$-lactose reduced the galectin-1 expression levels in the PSCs to a level similar to that in the single PCC line culture $(P>0.05)$ (Figure 2a, b). This finding indicates that, as an inhibitor of galectin-1, $\beta$-lactose hindered the ability of PSCs-secreted galectin-1 to act on PCCs, confirming that the increased expression of galectin-1 in PCC lines was at
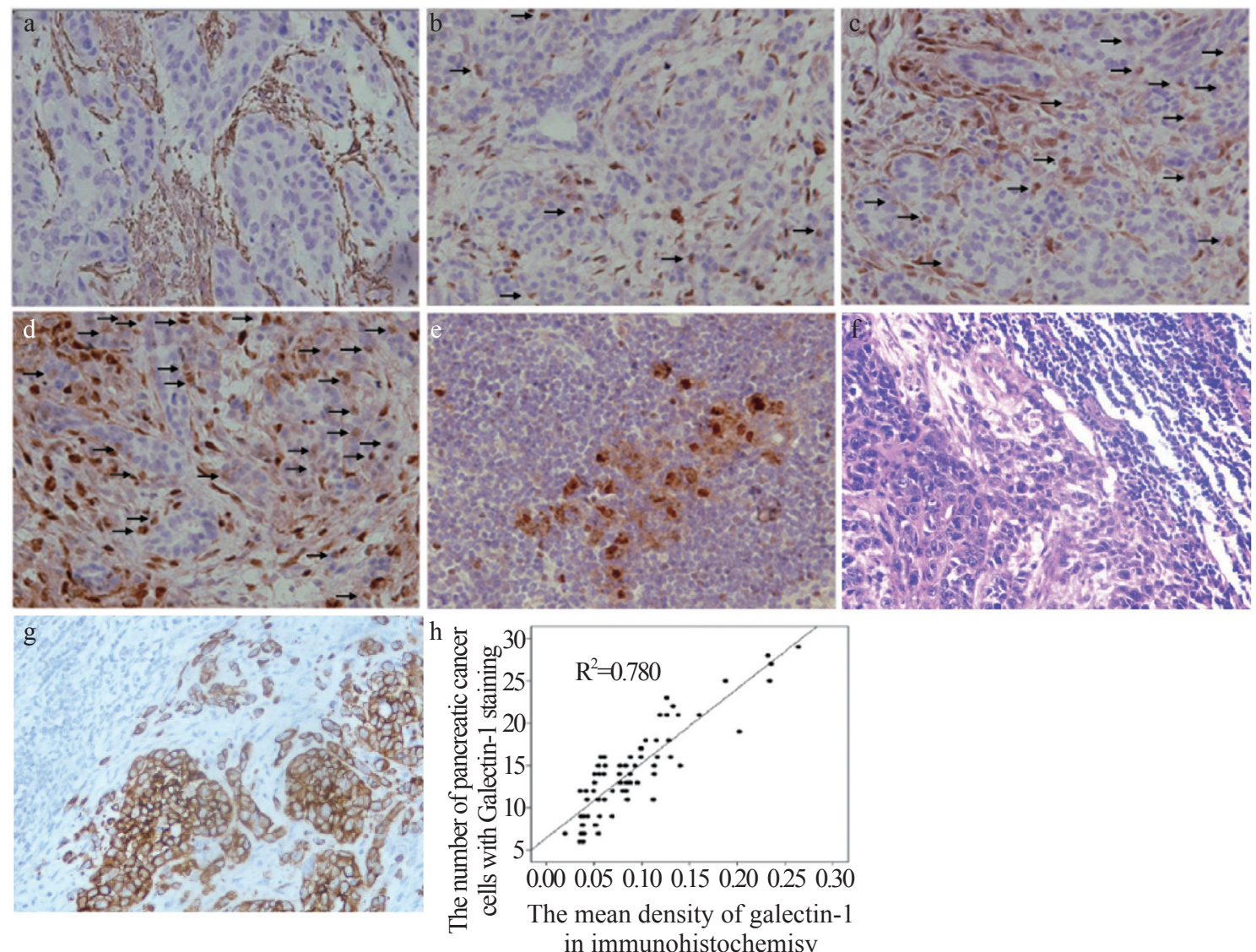

Figure 1 Immunohistochemical staining of galectin-1. Representative tissues samples of chronic pancreatitis (a), PDAC (b-d), and metastatic lymph nodes (e-g). (b-d) Well-differentiated (b), moderately differentiated (c), and poorly differentiated (d) PDAC tissues. (e-g) Metastatic lymph nodes were stained for galectin-1 (e), HE (f), and cytokeratin (g). (h) The correlation of the mean density of galectin-1 in PCCs and PDAC tissues 
least partly induced by the galectin-1 expression of PSCs.

\section{Endogenous galectin-1 promotes the malignant biological behavior of PANC-1 cells}

To assess the influence of endogenous galectin- 1 on the biological behavior of PCCs, galectin-1 was overexpressed in PANC-1 cells using recombinant lentiviruses. qRT-PCR and Western blotting showed that the galectin-1 expression in PANC-1 cells was $>4$-fold that of the untransfected control PANC-1 cells (Figure 2c-g). The colony formation a

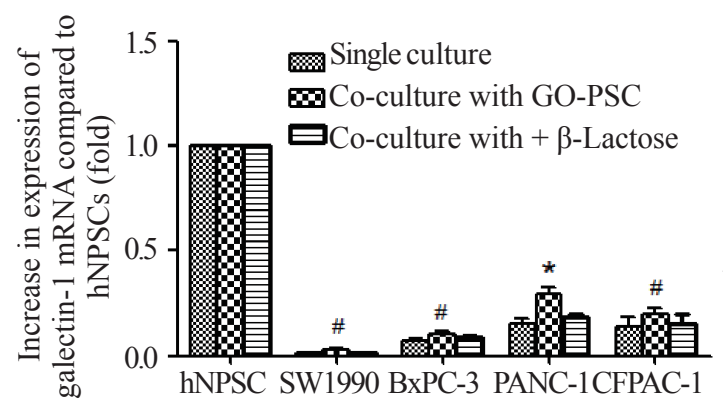

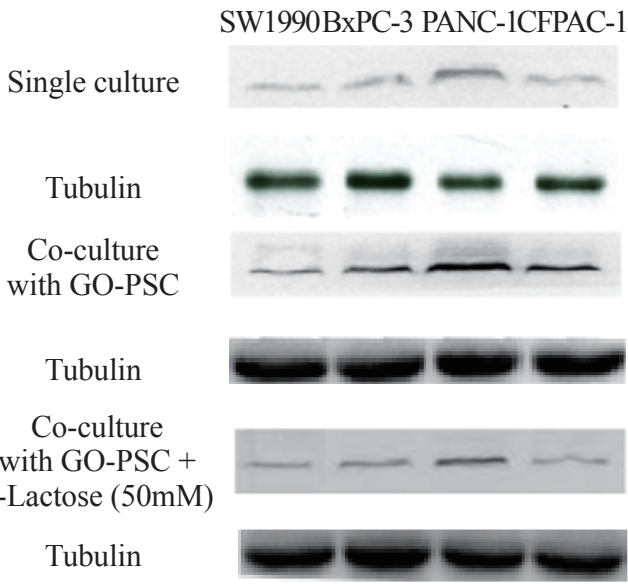

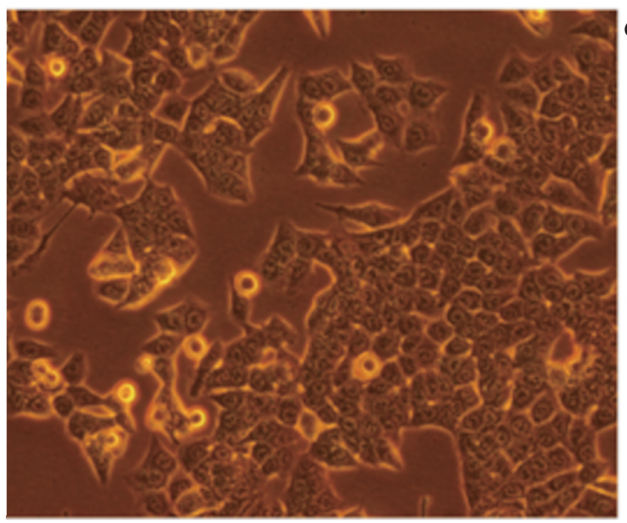

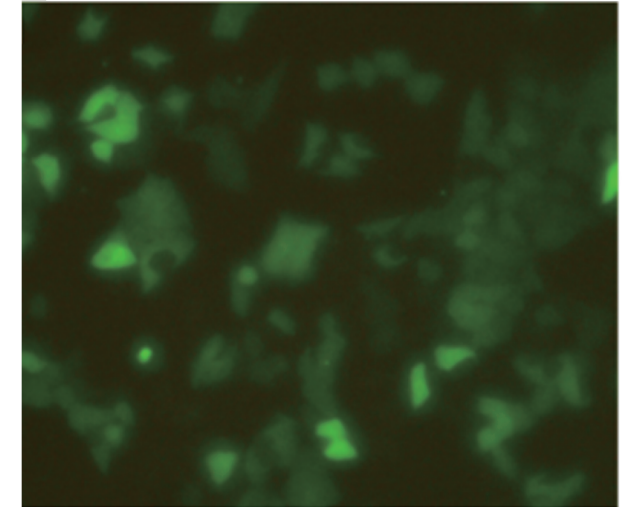

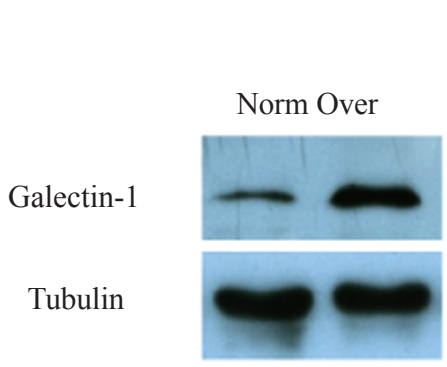

$\mathrm{f}$

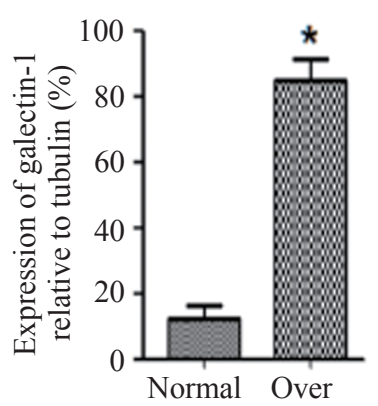

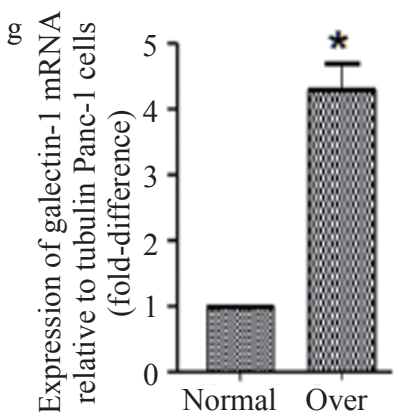

Figure 2 Galectin-1 expression was detected in PSC and PCC lines. Galectin-1 was mainly expressed in PSCs, while low levels of galectin-1 expression were detected in the PCC lines (a). Co-culturing galectin-1-overexpressing PSCs (GO-PSC) with PCC lines increased the galectin-1 expression in the PCCs (b). $* P<0.01$ vs. single culture, $\# P<0.05$ vs. single culture. (c, d) Green fluorescent protein-expressing PANC-1 cells transduced with pHAGE lentivirus were selected using flow cytometry and were observed under epifluorescence and light microscopy, which confirmed the presence of the galectin-1-expressing lentivirus in all cells. (e, f) Representative Western blot results showing the increased human galectin-1 expression in PANC-1 cells transduced with the galectin-1 lentivirus (Over). (g) Quantitative analysis of the differentiated phenotype of PANC-1 cells. Human galectin-1 mRNA expression was increased in the Over group. ${ }^{*} P<0.01$ vs. control PCCs 
assay showed that 14 days after seeding under anchorageindependent conditions, the PANC-1 cells overexpressing galectin-1 formed significantly more colonies than the control PANC-1 cells $(P=0.0176)$ (Figure 3a, 3g). The wound healing assay similarly showed more migration of the galectin-1-overexpressing PANC-1 cells compared to the control cells $24 \mathrm{~h}$ after wounding $(P<0.01)$ (Figure $3 \mathrm{~b}, 3 \mathrm{~h}$ ). PANC-1 cells overexpressing galectin-1 had significantly increased invasive ability compared to the control cells $(P=$ 0.0469) (Figure 3c, 3i).

The MTT assay showed that PANC-1 cells overexpressing galectin-1 had significantly increased proliferation compared to the control cells at $48 \mathrm{~h}(P<$ $0.05), 72 \mathrm{~h}(P<0.01)$, and $96 \mathrm{~h}(P<0.01)$ (Figure $3 \mathrm{f})$.
More importantly, galectin-1-overexpressing PANC-1 cells had increased BCL-2 and proliferating cell nuclear antigen (PCNA) expression $(P<0.01)$ (Figure 3e, 3k) and decreased Bax expression $(P<0.05)$ (Figure 3e, 3k), further supporting the pro-proliferation effect of galectin-1 on PANC-1 cells and also indicating that galectin-1 might have anti-apoptotic effects. In addition, the TUNEL assay showed that galectin-1-overexpressing PANC-1 cells had an obviously decreased apoptosis rate $(P=0.0465)$, which further supports the anti-apoptotic activity of galectin-1 (Figure 3d, 3j). These results indicate that endogenous galectin-1 promotes PANC-1 cell proliferation, growth, migration, invasion, and anti-apoptosis effects, which contribute to the malignant biological behavior of the cells.
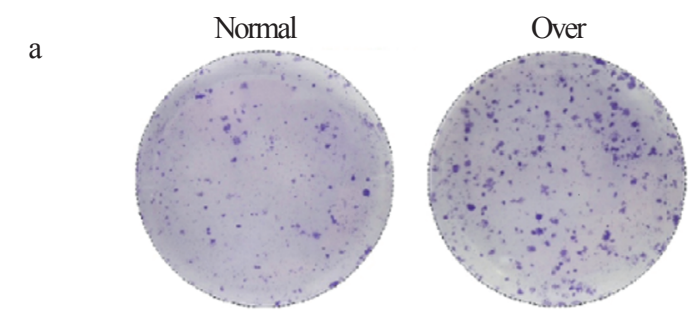

b
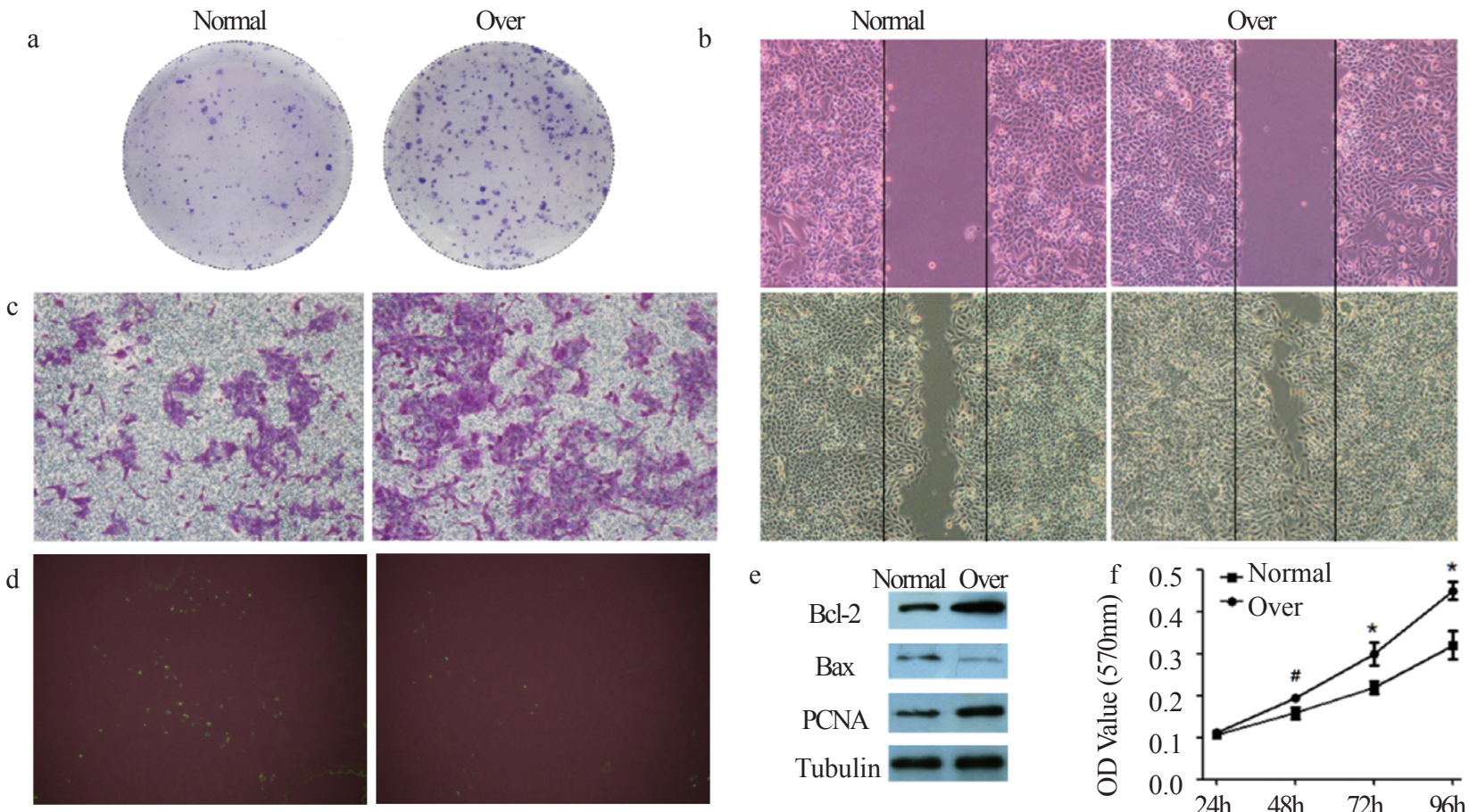

$\mathrm{e}$
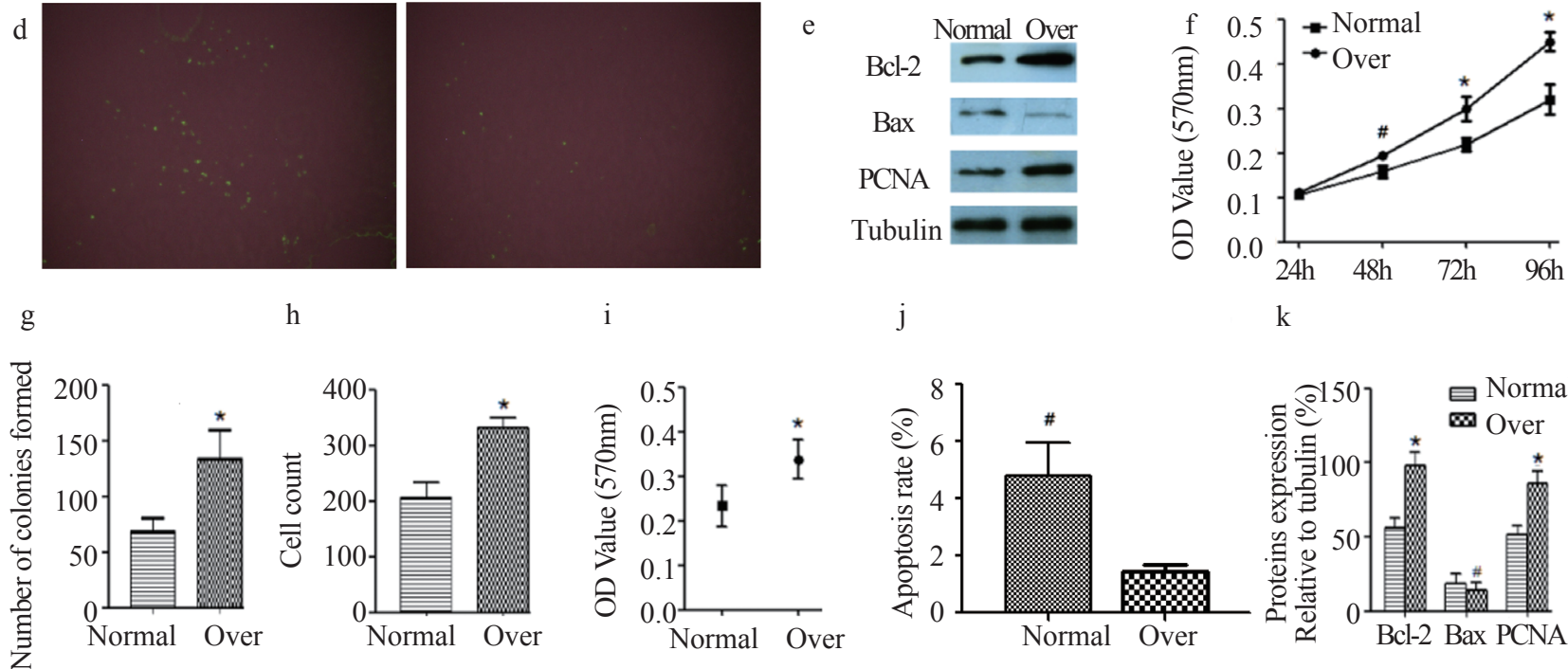

h

i

j

$\mathrm{k}$
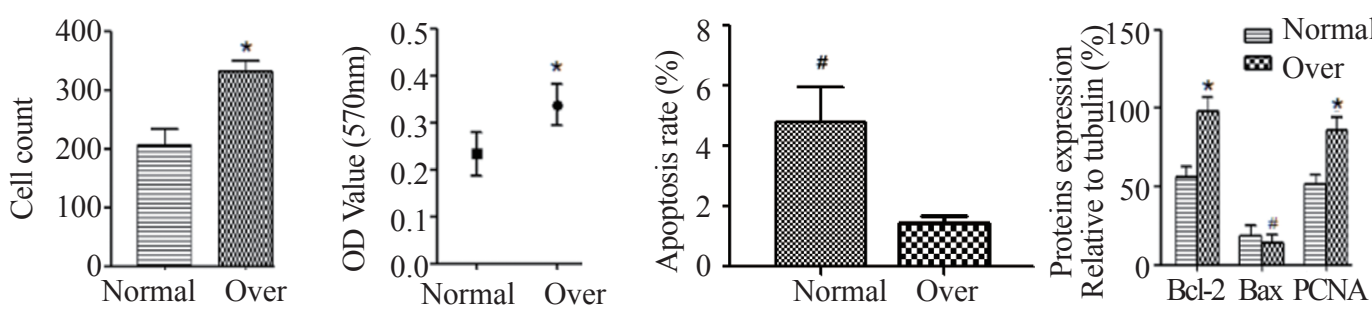

Figure 3 Effects of galectin-1 overexpression on PCC cells. (a, g) The colony formation assay showing that galectin-1-overexpressing PANC-1 cells (Over) had a significantly increased ability to form cells clones. $(b, h)$ The wound-healing assay showing that galectin-1 overexpression significantly increased PANC-1 cell migration. (c, i) Transwell assays showed that galectin-1 overexpression significantly increased PANC-1 cell invasion. (f) MTT assays showed that galectin-1 overexpression significantly increased PANC-1 cell proliferation. (d, j) The TUNEL assay showed that galectin- 1 overexpression significantly decreased PANC-1 cell apoptosis. $* P<0.05$ vs. Control (normal) PCCs. (e, k) Galectin-1 overexpression in PANC-1 cells increased BCL-2 and PCNA expression, and decreased Bax expression, indicating that it promotes PANC-1 cell proliferation and decreases apoptosis. ${ }^{*} P<0.01$ vs. Control (normal) PCCs, ${ }^{*} P<0.05$ vs. Control (normal) PCCs. OD, optical density 


\section{Influence of endogenous galectin-1 in PCCs on the establishment and growth of tumors}

In order to evaluate the influence of endogenous galectin-1 in PCCs on tumor progression in vivo, we embedded PANC-1 cells subcutaneously into the flanks (left, galectin-1-overexpressing cells; right, control cells) of male nude mice. Compared with the control side, the tumor volume of the galectin-overexpressing side increased significantly more beginning on day 10 after implantation (Figure $4 a, b$ ). At 25 days after implantation, the mean volume and weight of tumors on the galectin-overexpressing sides were 877.25 $\pm 89.75 \mathrm{~mm}^{3}$ and $0.85 \pm 0.10 \mathrm{~g}$, respectively, while those of the control side were $549.75 \pm 63.80 \mathrm{~mm}^{3}$ and $0.38 \pm 0.25$ $\mathrm{g}$, respectively (Figure 4b, c). The results clearly showed that the tumors grew more quickly and were when the cells overexpressed galectin-1 $(P<0.01)$. In addition, the EdU incorporation assay revealed that the galectin-overexpressing tumors had higher proliferation than the control tumors (Figure 4d, e). The results show that the overexpression of endogenous galectin-1 in PCCs increase tumor formation and growth.

\section{Discussion}

It was previously established that PSCs in the PDAC tumor microenvironment can boost tumor growth, invasion, metastasis, tumor hypoxia, immune evasion, and drug resistance $[31,32]$. We evaluated the influence of galectin-1 in PSCs, and found that they induced galectin-1 expression in PCCs, which in turn promoted the malignant biological behavior of PDAC. Histologically, galectin-1 is mostly expressed in the PDAC stroma (the source of PSCs) [23], but in the current study, some PSC-adjacent PCCs also had obvious galectin-1 staining, and there was a strong positive association between this staining and the malignant behavior of PDAC. Furthermore, we showed that high galectin-1 level in PSCs increased the expression of galectin-1 in the PANC-1 PCC cells, and galectin-1 overexpression in the PANC-1 cells enhanced PCC growth, proliferation, and invasion, increased PCNA and BCL-2 expression, decreased Bax expression and increased tumor establishment and growth.

PCNA is a known biomarker of proliferation, and its overexpression is linked to the progression of PDAC [33]. a

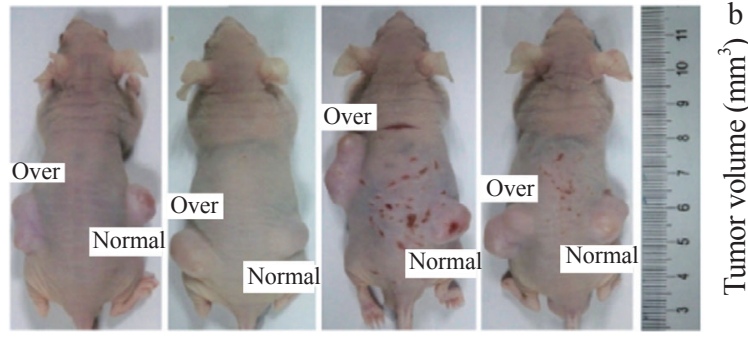

d

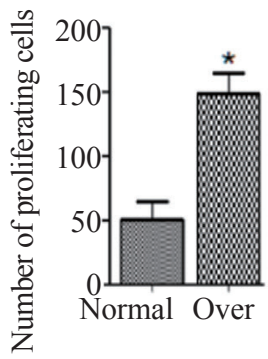

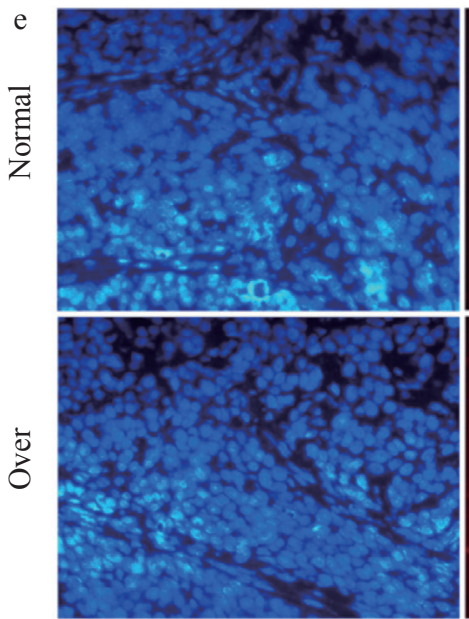
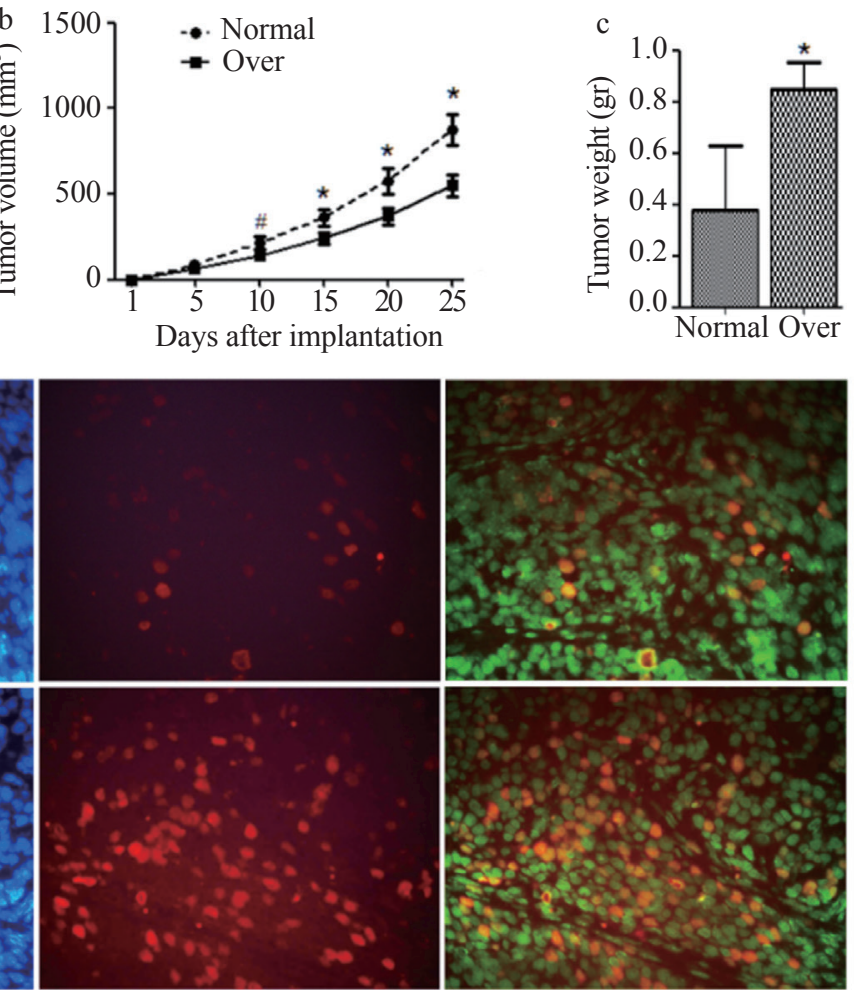

Figure 4 In vivo animal model. (a, g) The colony formation assay showing that galectin-1-overexpressing PANC-1 cells (Over) had a significantly increased ability to form cells clones. $(b, h)$ The wound-healing assay showing that galectin- 1 overexpression significantly increased PANC-1 cell migration. (c, i) Transwell assays showed that galectin-1 overexpression significantly increased PANC-1 cell invasion. (f) MTT assays showed that galectin-1 overexpression significantly increased PANC-1 cell proliferation. (d, j) The TUNEL assay showed that galectin-1 overexpression significantly decreased PANC-1 cell apoptosis. ${ }^{*} P<0.05$ vs. Control (normal) PCCs. (e, k) Galectin-1 overexpression in PANC-1 cells increased BCL-2 and PCNA expression, and decreased Bax expression, indicating that it promotes PANC-1 cell proliferation and decreases apoptosis. ${ }^{*} P<0.01$ vs. Control (normal) $P C C s,{ }^{\sharp} P<0.05$ vs. Control (normal) PCCs. OD, optical density 
BCL-2 is a typical anti-apoptotic protein and its overexpression contributes to the progression and metastasis of various cancers [34,35]. Bax has 40\% homology with Bcl-2, but its overexpression was proven to promote cell apoptosis in PDAC, and it is currently considered to be a pro-apoptotic protein. In addition, the TUNEL assay confirmed that galectin-1 has anti-apoptotic effects in PCC cells [36]. In summary, the results indicate that the expression of galectin- 1 by PSCs and the interaction between PSCs and PCC cells may be important in the initiation and progression of PDAC.

Cancer cells typically overexpress galectin-1, and it functions in tumor cell adhesion, invasion, angiogenesis, the epithelial-mesenchymal transition (EMT) and metastasis [37-39]. It is being increasingly recognized as a vital protein that mediates the development of an immunosuppressive microenvironment, allowing for tumor growth via promoting angiogenesis and local immunosuppression [40]. Galectin-1 can function via the TGF- $\beta 1 / \mathrm{Smad}$, TNF- $\alpha / \mathrm{NF}$ $\mathrm{k} \beta$, and Notch signaling pathways, promoting a variety of malignant behaviors [41]. Galectin-1 has been considered a potential target for cancer treatment by using relevant inhibitors [42]. Moreover, our previous research [2,23,24] demonstrated that $\beta$-lactose, an antagonist of galectin-1, could reduce the malignant behavior of PDAC. In PDAC, galectin-1 induced a series of tumor-related processes, such as invasion, angiogenesis, MMP2/MMP9 expression and the EMT, which could all contribute to the growth of pancreatic cancer cells [43]. Galectin-1 was initially thought to be expressed exclusively in activated PSCs, where its expression promoted cancer cell growth and correlated with a poorer survival [22,23]. Further observations revealed galectin-1 staining in some PSC-adjacent PCCs, and this positively correlated with the degree of PDAC differentiation. In addition, cancer cells in the metastatic lymph nodes in PDAC showed strong galectin-1 staining. Moreover, galectin-1 staining within the lymphocyte areas of the tumor was significantly associated with a poorer outcome [44]. These results indicate that increased galectin-1 expression in PCCs may induce the malignant behavior of cancer cells and promote PDAC progression. Increased evidence indicates that PSCs in the tumor microenvironment cross-talk with tumor cells to promote PDAC development [45], and the proteins or cytokines expressed by the PSCs and PCCs, and induced by their interactions, play a vital role in malignancy, but the mechanism(s) have been unclear.

To clarify whether PSCs with high galectin-1 expression can induce galectin-1 expression in PCCs and whether it is related to the malignant biological behavior of PDAC, we co-cultured PSCs and PCCs. We discovered that PSCs with high galectin-1 expression could promote galectin-1 expression in PCCs, while treatment of the cultures with $\beta$-lactose decreased the expression, confirming that the galectin-1 expressed by PSCs was at least partly responsible for the increase in galectin-1 in PCCs. Furthermore, PANC-1 cells transfected with recombinant adenovirus in vitro to overexpress galectin-1 had increased growth, proliferation, invasion, and anti-apoptotic activity compared to control cells, which was confirmed in the PANC-1 xenograft model.

However, the full impact of the interaction between PSCs and PCCs with regard to galectin-1 induction and the subsequent promotion of malignant behavior by PDAC requires further investigation. At present, the following are considered to be implicated in these effects: first, activated PSCs can induce the epithelial-mesenchymal transition (EMT) in PCCs [45-47], and galectin-1 can also trigger the EMT in cancer cells [38,39,48-50], therefore, mesenchymal-phenotype PCCs may have increased galectin-1 expression. Second, PSCs can also induce stem cell-like phenotypes in PCCs, resulting in resistance to conventional therapies, distant metastasis, and recurrence [51-54]. Third, galectin-1 is overexpressed in cancer stem cells [55], and these cells are usually found on the tumor periphery, where the invasive front is located. This finding indicates that the stem cell-like cancer cells may have increased galectin-1 expression and may induce or increase the progression of PDAC.

There have been a few previous studies on the biological influence of galectin-1-overexpressing PSCs on PCCs $[23,30,56,57]$. Based on those studies and the present findings, we hypothesize that after they come into contact with the surrounding stroma, the PSCs begin to express galectin-1 on the membrane. Moreover, high galectin-1 expression in the stroma can lead to the desmoplastic reaction via paracrine signaling. We believe that the galectin-1 secreted into the tumor microenvironment by PSCs acts on fibroblasts via both paracrine and autocrine pathways to promote cell proliferation, invasion and migration.

In conclusion, our study indicates that the overexpression of galectin-1 in PSCs enhances the expression of galectin-1 in PCCs. This process promotes PCC proliferation, anti-apoptosis, invasion, and tumor establishment and growth in an autocrine manner. Our previous study reported that PSC-derived galectin-1 can increase PDAC progression and lead to a poorer survival [23]. Thus, targeting galectin-1 on both PSCs and PCCs might inhibit PDAC progression. However, the specific mechanism and method to specifically target these cells requires further study.

\section{Acknowledgments}

We thank Prof. Lu Chun (Department of Microbiology and Immunology, Nanjing Medical University, China) for kindly providing the lentiviral packaging system consisting of pHAGE-CMVMCS-IZs Green, psPAX2, and pMD2.G.

\section{Conflicts of Interests}

The Authors declare that there is no conflict of interest.

\section{Funding}

This work was supported by grants from the National 
Natural Science Funding of China (No. 81572344) and the Training Project of Key Talents of Youth Medicine in Jiangsu province, China (No. QNRC2016330).

\section{References}

1. Jemal A, Siegel R, Xu J, Ward E. Cancer statistics, 2010. CA Cancer J Clin 2010; 60(5):277-300.

2. Tang D, Wang D, Yuan Z, Xue X, Zhang Y, An Y, Chen J, Tu M, Lu Z, Wei J, Jiang K, Miao Y. Persistent activation of pancreatic stellate cells creates a microenvironment favorable for the malignant behavior of pancreatic ductal adenocarcinoma. Int J Cancer 2012;123(5):993-1003. 3. Sperti C, Pasquali C, Piccoli A, Pedrazzoli S. Recurrence after resection for ductal adenocarcinoma of the pancreas. World J Surg 1997;21(2):95-200.

4. Zhang Y, Frampton AE, Kyriakides C, Bong JJ, Habib N, Ahmad R, Jiao LR. Loco-recurrence after resection for ductal adenocarcinoma of the pancreas: predictors and implications for adjuvant chemoradiotherapy. J Cancer Res Clin Oncol 2012;138(6):1063-71.

5. Farrow B, Albo D, Berger DH. The role of the tumor microenvironment in the progression of pancreatic cancer. J Surg Res 2008;149(2):319-28.

6. Erkan M, Reiser-Erkan C, Michalski CW, Kleeff J. Tumor microenvironment and progression of pancreatic cancer. Exp Oncol 2010;32(3):128-31.

7. Bachem MG, Schneider E, Gross H, Weidenbach H, Schmid RM, Menke A, Siech M, Beger H, Grunert A, Adler G. Identification, culture, and characterization of pancreatic stellate cells in rats and humans. Gastroenterology 1998;115(2):421-32.

8. Apte MV, Park S, Phillips PA, Santucci N, Goldstein D, Kumar RK, Ramm GA, Buchler M, Friess H, McCarroll JA, Keogh G, Merrett N, Pirola R, Wilson JS. Desmoplastic reaction in pancreatic cancer: role of pancreatic stellate cells. Pancreas 2004;29(3):179-87.

9. Masamune A, Kikuta K, Watanabe T, Satoh K, Hirota M, Shimosegawa T. Hypoxia stimulates pancreatic stellate cells to induce fibrosis and angiogenesis in pancreatic cancer. Am J Physiol Gastrointest Liver Physiol 2008;295(4):G709-17.

10. Xu Z, Vonlaufen A, Phillips PA, Fiala-Beer E, Zhang X, Yang L, Biankin AV, Goldstein D, Pirola RC, Wilson JS, Apte MV. Role of pancreatic stellate cells in pancreatic cancer metastasis. Am J Pathol 2010;177(5):2585-96.

11. Jiang X, Abiatari I, Kong B, Erkan M, De Oliveira T, Giese NA, Michalski CW, Friess H, Kleeff J. Pancreatic islet and stellate cells are the main sources of endocrine gland-derived vascular endothelial growth factor/prokineticin-1 in pancreatic cancer. Pancreatology 2009;9(1-2):165-72.

12. Li X, Ma Q, Xu Q, Duan W, Lei J, Wu E. Targeting the cancer-stroma interaction: a potential approach for pancreatic cancer treatment. Curr Pharm Des 2012;18(17): 2404-15.

13. Apte MV, Wilson JS. Dangerous liaisons: pancreatic stellate cells and pancreatic cancer cells. J Gastroenterol Hepatol 2012;27 Suppl 2:69-74.

14. Kang R, Tang D. Autophagy in pancreatic cancer pathogenesis and treatment. Am J Cancer Res 2012;2(4):383-96.

15. Van Laethem JL, Verslype C, Iovanna JL, Michl P, Conroy T, Louvet C, Hammel P, Mitry E, Ducreux M, Maraculla T, Uhl W, Van
Tienhoven G, Bachet JB, Marechal R, Hendlisz A, Bali M, Demetter P, Ulrich F, Aust D, Luttges J, Peeters M, Mauer M, Roth A, Neoptolemos JP, Lutz M. New strategies and designs in pancreatic cancer research: consensus guidelines report from a European expert panel. Ann Oncol 2012;23(3):570-6.

16. Perillo NL, Marcus ME, Baum LG. Galectins: versatile modulators of cell adhesion, cell proliferation, and cell death. J Mol Med (Berl) 1998;76(6):402-12.

17. Wu MH, Hong TM, Cheng HW, Pan SH, Liang YR, Hong HC, Chiang WF, Wong TY, Shieh DB, Shiau AL, Jin YT, Chen YL. Galectin-1-mediated tumor invasion and metastasis, up-regulated matrix metalloproteinase expression, and reorganized actin cytoskeletons. Mol Cancer Res 2009;7(3):311-8.

18. Thijssen VL, Postel R, Brandwijk RJ, Dings RP, Nesmelova I, Satijn S, Verhofstad N, Nakabeppu Y, Baum LG, Bakkers J, Mayo KH, Poirier F, Griffioen AW. Galectin-1 is essential in tumor angiogenesis and is a target for antiangiogenesis therapy. Proc Natl Acad Sci U S A 2006,103(43):15975-80.

19. Kovacs-Solyom F, Blasko A, Fajka-Boja R, Katona RL, Vegh L, Novak J, Szebeni GJ, Krenacs L, Uher F, Tubak V, Kiss R, Monostori E. Mechanism of tumor cell-induced T-cell apoptosis mediated by galectin-1. Immunology Lett 2010;127(2):108-18.

20. Berberat PO, Friess H, Wang L, Zhu Z, Bley T, Frigeri L, Zimmermann A, Buchler MW. Comparative analysis of galectins in primary tumors and tumor metastasis in human pancreatic cancer. J Histochem Cytochem 2001;49(4):539-49.

21. Masamune A, Satoh M, Hirabayashi J, Kasai K, Satoh K, Shimosegawa T. Galectin-1 induces chemokine production and proliferation in pancreatic stellate cells. Am J Physiol Gastrointest Liver Physiol 2006,290(4):G729-36.

22. Xue X, Lu Z, Tang D, Yao J, An Y, Wu J, Li Q, Gao W, Xu Z, Qian Z, Dai C, Wei J, Miao Y, Jiang K. Galectin-1 secreted by activated stellate cells in pancreatic ductal adenocarcinoma stroma promotes proliferation and invasion of pancreatic cancer cells: an in vitro study on the microenvironment of pancreatic ductal adenocarcinoma. Pancreas 2011;40(6):832-9.

23. Tang D, Zhang J, Yuan Z, Gao J, Wang S, Ye N, Li P, Gao S, Miao Y, Wang D, Jiang K. Pancreatic satellite cells derived galectin-1 increase the progression and less survival of pancreatic ductal adenocarcinoma. PloS one 2014,9(3):e90476.

24. Tang D, Gao J, Wang S, Yuan Z, Ye N, Chong Y, Xu C, Jiang X, Li B, Yin W, Miao Y, Wang D, Jiang K. Apoptosis and anergy of T cell induced by pancreatic stellate cells-derived galectin-1 in pancreatic cancer. T Tumour Biol 2015;36(7):5617-26.

25. Masamune A, Kikuta K, Watanabe T, Satoh K, Satoh A, Shimosegawa T. Pancreatic stellate cells express Toll-like receptors. J Gastroenterol 2008;43(5):352-62.

26. Sun H, Chen L, Zhou W, Hu L, Li L, Tu Q, Chang Y, Liu Q, Sun X, Wu M, Wang $\mathrm{H}$. The protective role of hydrogen-rich saline in experimental liver injury in mice. J Hepatol 2011;54(3):471-80.

27. Chen X, Iliopoulos D, Zhang Q, Tang Q, Greenblatt MB, Hatziapostolou M, Lim E, Tam WL, Ni M, Chen Y, Mai J, Shen H, Hu DZ, Adoro S, Hu B, Song M, Tan C, Landis MD, Ferrari M, Shin SJ, Brown M, Chang JC, Liu XS, Glimcher LH. XBP1 promotes triple-negative breast cancer by controlling the HIF1 $\alpha$ pathway. Nature 
2014;508(7494):103-7.

28. Elmaagacli AH, Koldehoff M, Peceny R, Kleinhitpass L, Ottinger H, Beelen DW, Opalka B. WT1 and BCR-ABL specific small interfering RNA have additive effects in the induction of apoptosis in leukemic cells. Haematologica 2005;90(3):326-34.

29. Xue X, Zhang Y, Zhi Q, Tu M, Xu Y, Sun J, Wei J, Lu Z, Miao Y, Gao W. MiR200-upregulated Vasohibin 2 promotes the malignant transformation of tumors by inducing epithelial-mesenchymal transition in hepatocellular carcinoma. Cell Commun Signal 2014;12:62.

30. Tang D, Yuan Z, Xue X, Lu Z, Zhang Y, Wang H, Chen M, An Y, Wei J, Zhu Y, Miao Y, Jiang K. High expression of Galectin-1 in pancreatic stellate cells plays a role in the development and maintenance of an immunosuppressive microenvironment in pancreatic cancer. Int J Cancer 2012;130(10):2337-48.

31. Bynigeri RR, Jakkampudi A, Jangala R, Subramanyam C, Sasikala M, Rao GV, Reddy DN, Talukdar R. Pancreatic stellate cell: Pandora's box for pancreatic disease biology. World J Gastroenterol 2017;23(3):382-405.

32. Endo $S$, Nakata $K$, Ohuchida $K$, Takesue $S$, Nakayama H, Abe T, Koikawa K, Okumura T, Sada M, Horioka K, Zheng B, Mizuuchi Y, Iwamoto C, Murata M, Moriyama T, Miyasaka Y, Ohtsuka T, Mizumoto K, Oda Y, Hashizume M, Nakamura M. Autophagy is required for activation of pancreatic stellate cells, associated with pancreatic cancer progression and promotes growth of pancreatic tumors in mice. Gastroenterology 2017;152(6):1492-1506.e24.

33. Yue H, Na YL, Feng XL, Ma SR, Song FL, Yang B. Expression of p57kip2, Rb protein and PCNA and their relationships with clinicopathology in human pancreatic cancer. World J Gastroenterol 2003;9(2):377-80

34. Baretton GB, Diebold J, Christoforis G, Vogt M, Müller C, Dopfer K, Schneiderbanger K, Schmidt M, Löhrs U. Apoptosis and immunohistochemical bcl-2 expression in colorectal adenomas and carcinomas. Aspects of carcinogenesis and prognostic significance. Cancer 2015;77(2):255-64.

35. Hanada M, Aimésempé C, Sato T, Reed JC. Structure-function analysis of Bcl-2 protein. Identification of conserved domains important for homodimerization with Bcl-2 and heterodimerization with Bax. J Biol Chem 1995;270(20):11962-9.

36. Dong M, Zhou JP, Zhang H, Guo KJ, Tian YL, Dong YT. Clinicopathological significance of Bcl-2 and Bax protein expression in human pancreatic cancer. World J Gastroenterol 2005;11(18):2744-7.

37. Ito K, Ralph SJ. Inhibiting galectin-1 reduces murine lung metastasis with increased CD4(+) and CD8 (+) T cells and reduced cancer cell adherence. Clin Exp Metastasis 2012;29(6):561-72.

38. Park GB, Kim D. TLR4-mediated galectin-1 production triggers epithelial-mesenchymal transition in colon cancer cells through ADAM10- and ADAM17-associated lactate production. Mol Cell Biochem 2017;425(1-2):191-202.

39. Chong Y, Tang D, Xiong Q, Jiang X, Xu C, Huang Y, Wang J, Zhou H, Shi Y, Wu X. Galectin-1 from cancer-associated fibroblasts induces epithelial-mesenchymal transition through $\beta 1$ integrin-mediated upregulation of Gli1 in gastric cancer. J Exp Clin Cancer Res 2016;35(1):175.

40. Ito K, Stannard K, Gabutero E, Clark AM, Neo SY, Onturk S, Blanchard H, Ralph SJ. Galectin-1 as a potent target for cancer therapy: role in the tumor microenvironment. Cancer Metastasis Rev 2012;31(34):763-78.

41. Tang D, Wu Q, Zhang J, Zhang H, Yuan Z, Xu J, Chong Y, Huang Y, Xiong Q, Wang S. Galectin-1 expression in activated pancreatic satellite cells promotes fibrosis in chronic pancreatitis/pancreatic cancer via the TGF- $\beta 1$ /Smad pathway. Oncol Rep 2018;39(3):1347-55.

42. Astorgues-Xerri L, Riveiro ME, Tijeras-Raballand A, Serova M, Neuzillet C, Albert S, Raymond E, Faivre S. Unraveling galectin-1 as a novel therapeutic target for cancer. Cancer Treat Rev 2014;40(2):30719.

43. Wu Q, Tian Y, Zhang J, Zhang H, Gu F, Lu Y, Zou S, Chen Y, Sun P, Xu M, Sun X, Xia C, Chi H, Ying Zhu A, Tang D, Wang D. Functions of pancreatic stellate cell-derived soluble factors in the microenvironment of pancreatic ductal carcinoma. Oncotarget 2017;8(60):10272138.

44. Chawla S, Warren TA, Wockner LF, Lambie DL, Brown IS, Martin TP, Khanna R, Leggatt GR, Panizza BJ. Galectin-1 is associated with poor prognosis in patients with cutaneous head and neck cancer with perineural spread. Cancer Immunol Immunother 2016;65(2):213-22.

45. Tang D, Wang D, Yuan Z, Xue X, Zhang Y, An Y, Chen J, Tu M, Lu Z, Wei J, Jiang K, Miao Y. Persistent activation of pancreatic stellate cells creates a microenvironment favorable for the malignant behavior of pancreatic ductal adenocarcinoma. Int J Cancer 2013;132(5):9931003.

46. Wu YS, Chung I, Wong WF, Masamune A, Sim MS, Looi CY. Paracrine IL-6 signaling mediates the effects of pancreatic stellate cells on epithelial-mesenchymal transition via Stat3/Nrf2 pathway in pancreatic cancer cells. Biochim Biophys Acta Gen Subj 2017;1861(2):296-306.

47. Karnevi E, Rosendahl AH, Hilmersson KS, Saleem MA, Andersson R. Impact by pancreatic stellate cells on epithelial-mesenchymal transition and pancreatic cancer cell invasion: Adding a third dimension in vitro. Exp Cell Res 2016;346(2):206-15.

48. Kikuta K, Masamune A, Watanabe T, Ariga H, Itoh H, Hamada S, Satoh K, Egawa S, Unno M, Shimosegawa T. Pancreatic stellate cells promote epithelial-mesenchymal transition in pancreatic cancer cells. Biochem Biophys Res Commun 2010;403(3-4):380-4.

49. Bacigalupo ML, Manzi M, Espelt MV, Gentilini LD, Compagno D, Laderach DJ, Wolfenstein-Todel C, Rabinovich GA, Troncoso MF. Galectin-1 triggers epithelial-mesenchymal transition in human hepatocellular carcinoma cells. J Cell Physiol 2015;230(6):1298-309.

50. Chong Y, Tang D, Gao J, Jiang X, Xu C, Xiong Q, Huang Y, Wang J, Zhou H, Shi Y, Wang D. Galectin-1 induces invasion and the epithelial-mesenchymal transition in human gastric cancer cells via non-canonical activation of the hedgehog signaling pathway. Oncotarget 2016;7(50):83611-26.

51. Chong Y, Tang D, Xiong Q, Jiang X, Xu C, Huang Y, Wang J, Zhou H, Shi Y, Wu X, Wang D. Galectin-1 from cancer-associated fibroblasts induces epithelial-mesenchymal transition through beta1 integrin-mediated upregulation of Gli1 in gastric cancer. J Exp Clin Cancer Res 2016;35(1):175.

52. Zhang PF, Li KS, Shen YH, Gao PT, Dong ZR, Cai JB, Zhang C, Huang XY, Tian MX, Hu ZQ, Gao DM, Fan J, Ke AW, Shi GM. Galectin-1 induces hepatocellular carcinoma EMT and sorafenib resistance by activating FAK/PI3K/AKT signaling. Cell Death Dis 2016;7:e2201. 53. Masamune A, Shimosegawa T. Pancreatic stellate cells: A dynamic 
player of the intercellular communication in pancreatic cancer. Clin Res Hepatol Gastroenterol 2015;39 Suppl 1:S98-103.

54. Al-Assar O, Demiciorglu F, Lunardi S, Gaspar-Carvalho MM, McKenna WG, Muschel RM, Brunner TB. Contextual regulation of pancreatic cancer stem cell phenotype and radioresistance by pancreatic stellate cells. Radiother Oncol 2014;111(2):243-51.

55. Hamada S, Masamune A, Shimosegawa T. Alteration of pancreatic cancer cell functions by tumor-stromal cell interaction. Front Physiol 2013;4:318.

56. Hamada S, Masamune A, Takikawa T, Suzuki N, Kikuta K, Hirota M, Hamada H, Kobune M, Satoh K, Shimosegawa T. Pancreatic stellate cells enhance stem cell-like phenotypes in pancreatic cancer cells.
Biochem Biophys Res Commun 2012;421(2):349-54.

57. Zhou X, Li D, Wang X, Zhang B, Zhu H, Zhao J. Galectin-1 is overexpressed in CD133+ human lung adenocarcinoma cells and promotes their growth and invasiveness. Oncotarget 2015;6(5):3111-22.

58. Qian D, Lu Z, Xu Q, Wu P, Tian L, Zhao L, Cai B, Yin J, Wu Y, Staveley-O’Carroll KF, Jiang K, Miao Y, Li G. Galectin-1-driven upregulation of SDF-1 in pancreatic stellate cells promotes pancreatic cancer metastasis. Cancer lett 2017;397:43-51.

59. Martinez-Bosch N, Navarro P. Targeting Galectin-1 in pancreatic cancer: immune surveillance on guard. Oncoimmunology 2014;3(8):e952201. 